\title{
Location and Number of Human Parathyroid Glands - A Postmortem Study
}

\author{
Sabiha Mahbub ${ }^{1}$, Shamim Ara $^{2}$, Abdul Alim ${ }^{3}$, Abu Sadat Mohammad Nurunnabi ${ }^{4}$ ABM Omar \\ Faruque $^{5}$, Rukshana Ahmed ${ }^{6}$, Segupta Kishwara ${ }^{7}$
}

\begin{abstract}
Context: The parathyroid gland, the last major organ to be recognized in humans, is an essential endocrine gland. The hormone secreted by the parathyroid gland provides a powerful mechanism for controlling extracellular calcium and phosphate concentrations. Knowledge of location and number of parathyroid gland is essential to surgeon, endocrinologist, sonologist and pathologist for better diagnosis and management of parathyroid diseases.
\end{abstract}

Study design: A descriptive type of study.

Place and period of study: Department of Anatomy, Dhaka Medical College, Dhaka from January 2008 to December 2008.

Materials: The present study was performed on post mortem parathyroid glands of 60 Bangladeshi people in different age groups. Total 207 parathyroid glands were taken from this 60 cadavers. The samples were collected from the unclaimed dead bodies within 24 hours after death that were under examination in the Department of Forensic Medicine of Dhaka Medical College, Dhaka.

Methods: The samples were divided into three different age groups ranging from 15 to 75 years. The three groups are group A (10-30 years), group B (31-60 years) and group C (61-90 years). All samples were studied morphologically.

Results: In the present study of 60 cadavers, 207 parathyroid glands were identified in relation to posterior border of thyroid lobe. And most of the superior parathyroid glands were found on the middle third of the posterior border of the thyroid lobe and most of the inferior parathyroid glands were found on the lower third of the posterior border of the thyroid lobe. In this study the highest number of parathyroid glands per person was four, found in about $63.333 \%$ of cases and lowest was one, found in $5 \%$ of cases, two parathyroid glands were found in $8.33 \%$ of cases and three parathyroid glands were found in $23.33 \%$ of cases. The average number of parathyroid glands per person was 3.45.

Conclusion: The parathyroid glands vary in number and location.

Key words: Location, number, parathyroid gland.

1. Assistant Professor, Department of Anatomy, Tairunnessa Memorial Medical College, Gazipur.

2. Professor and Head, Department of Anatomy, Dhaka Medical College, Dhaka.

3. Anaesthetist, Modhupur Upazila Health Complex, Tangail.

4. Medical Officer, Union Sub-centre, Shampur, Islampur, Jamalpur.

5. Associate Professor, Department of Anatomy, Tairunnessa Memorial Medical College, Gazipur.

6. Lecturer, Department of Anatomy, Dhaka Medical College, Dhaka.

7. Assistant Professor (cc), Department of Anatomy, Dhaka Medical College, Dhaka.

Correspondence: Dr. Sabiha Mahbub

\section{Introduction:}

The parathyroid glands, the last major organ to be recognized in humans, were discovered in 1880 by Ivar Sandstrom, a Swedish medical student, as recounted by Aidan Carney in his delightful essay on the subject ${ }^{1}$.

These glands are usually lying between the posterior lobar borders of the thyroid glands and its capsule. Usually there are two on each side, superior and inferior $^{2}$. Approximately $10 \%$ of the population will have one or more supernumerary glands and some will have fewer than four glands ${ }^{3}$. 
The position of the parathyroid glands in the neck is highly variable but usually predictable on the basis of their embryological origin ${ }^{3}$. It has been pointed out that the parathyroid glands usually have symmetric distribution-when one superior parathyroid gland is located in one place, the opposite parathyroid gland will be in the contralateral mirror image of that place ${ }^{1}$. The superior parathyroid glands are more constant in location than the inferior $^{2}$. Superior parathyroid glands are located most frequently near to the junction of the inferior thyroid artery and the recurrent laryngeal nerve, usually superior to the artery and posterior to the nerve, close to the posterior border of the thyroid ${ }^{3}$. The inferior glands usually lie near the inferior pole of the thyroid and are inferior to the inferior thyroid artery and anterior to the recurrent laryngeal nerve ${ }^{4}$. The inferior pair are more variably situated (related to their embryological development) and may be within the fascial thyroid sheath, below the inferior thyroid arteries and near the inferior lobar poles; or outside the sheath, immediately above an inferior thyroid artery; or in the thyroid gland near its inferior pole ${ }^{2}$.

\section{Materials and methods:}

The present study was performed on post mortem parathyroid glands of 60 Bangladeshi people of both sexes in different age groups ranging from 15 to 75 years. Total 207 parathyroid glands were taken from this 60 cadavers. The study was done from January 2008 to December 2008.

The human parathyroid glands were collected from unclaimed dead bodies that were under examination in the Department of Forensic Medicine of Dhaka Medical College, Dhaka from February 2008 to October 2008. After legal formalities and requisite permission from department of Forensic Medicine, the samples were collected within 24 hours of death without any sign of putrefaction. All the samples were collected from medico-legal cases. During collection appropriate age, sex, and cause of death were noted from morgue's record book. The samples were brought to the Department of Anatomy, Dhaka Medical College, Dhaka. The samples were tagged immediately, which was bearing a code number for subsequent identification. Soon after collection each sample was gently washed in tap water on a dissection tray. Blood and blood clots were removed as far as possible. Then the samples were fixed in $10 \%$ formol saline solution.

\section{Grouping of the Sample}

For convenience of description in relation to age the collected samples were divided into three groups (according to Panijan, et al. ${ }^{5}$ ).

Table-I

Grouping of the Sample in relation to age

\begin{tabular}{llcc}
\hline Group & $\begin{array}{l}\text { Age limit in } \\
\text { years }\end{array}$ & $\begin{array}{c}\text { No.of } \\
\text { person }\end{array}$ & $\begin{array}{c}\text { No.of parathyroid } \\
\text { glands }\end{array}$ \\
\hline A & $10-30$ & 27 & 93 \\
B & $31-60$ & 28 & 98 \\
C & $61-90$ & 5 & 16 \\
\hline
\end{tabular}

\section{Variables Studied}

- Location of parathyroid glands in relation to posterior border of thyroid lobe.

- Number of parathyroid glands identified.

- Number of paired parathyroid glands.

\section{Procedure of collection of sample}

From each cadaver the parathyroid glands were collected by "Block Dissection", using the following steps:

During postmortem examination, neck, thoracic cavity and the abdominal cavity were routinely exposed by midline incision from chin to symphysis pubis. In the neck region, incision was given carefully to avoid any damage to the isthmus or any part of the thyroid gland. The skin, along with the platysma was retracted laterally. The sternocleidomastoid muscles were cut in the middle and retracted laterally for the exposure of the thyroid gland. Then the sternocleidomastoid and the superior belly of omohyoid were displaced laterally. Cutting through the sternothyroid near its lower end and turning it upwards to the thyroid cartilage were done. The fascia from the lobes of the thyroid gland was removed, exposing its arteries and veins. Searching for parathyroid glands were done all through the 
posterior surface of the thyroid gland. Small yellowish-brown ductless parathyroid glands were embedded either in the posterior surface of the capsule of the thyroid gland or outside the capsule. Then the parathyroid glands were separated and collected ${ }^{6}$.

\section{Procedure of the Study}

Observation of number and location of parathyroid glands in relation to posterior border of thyroid lobe:

While searching for parathyroid glands on the posterior aspect, the pretracheal fascia was retracted laterally on both sides, thus exposing the posterior aspect of the thyroid gland. Usually by following the course of arterial twigs of inferior thyroid artery, parathyroid glands were identified. Colour and shape also helps in identification of the organs. Then the number of parathyroid glands were observed on both sides. Then the vertical distance between the upper and lower extents of the posterior border was measured with a slide caliper. The position of the parathyroid glands with respect to vertical length were noted and expressed as percentage of parathyroid glands in upper, middle and lower third of the posterior border of thyroid lobe ${ }^{6}$.

\section{Results:}

- Location of parathyroid glands in relation to posterior border of thyroid lobe:

Location of parathyroid glands in relation to posterior border of thyroid lobe is shown in Table-II and Fig.-1.1,1.2,1.3 and 1.4.

- Number of parathyroid glands identified: Number of parathyroid glands identified is shown in Table-III and Fig.-2.

- Number of paired parathyroid glands: Number of paired parathyroid glands is shown in Table-IV and Fig.-3.

Table-II

Location of parathyroid glands in relation to posterior border of thyroid lobe

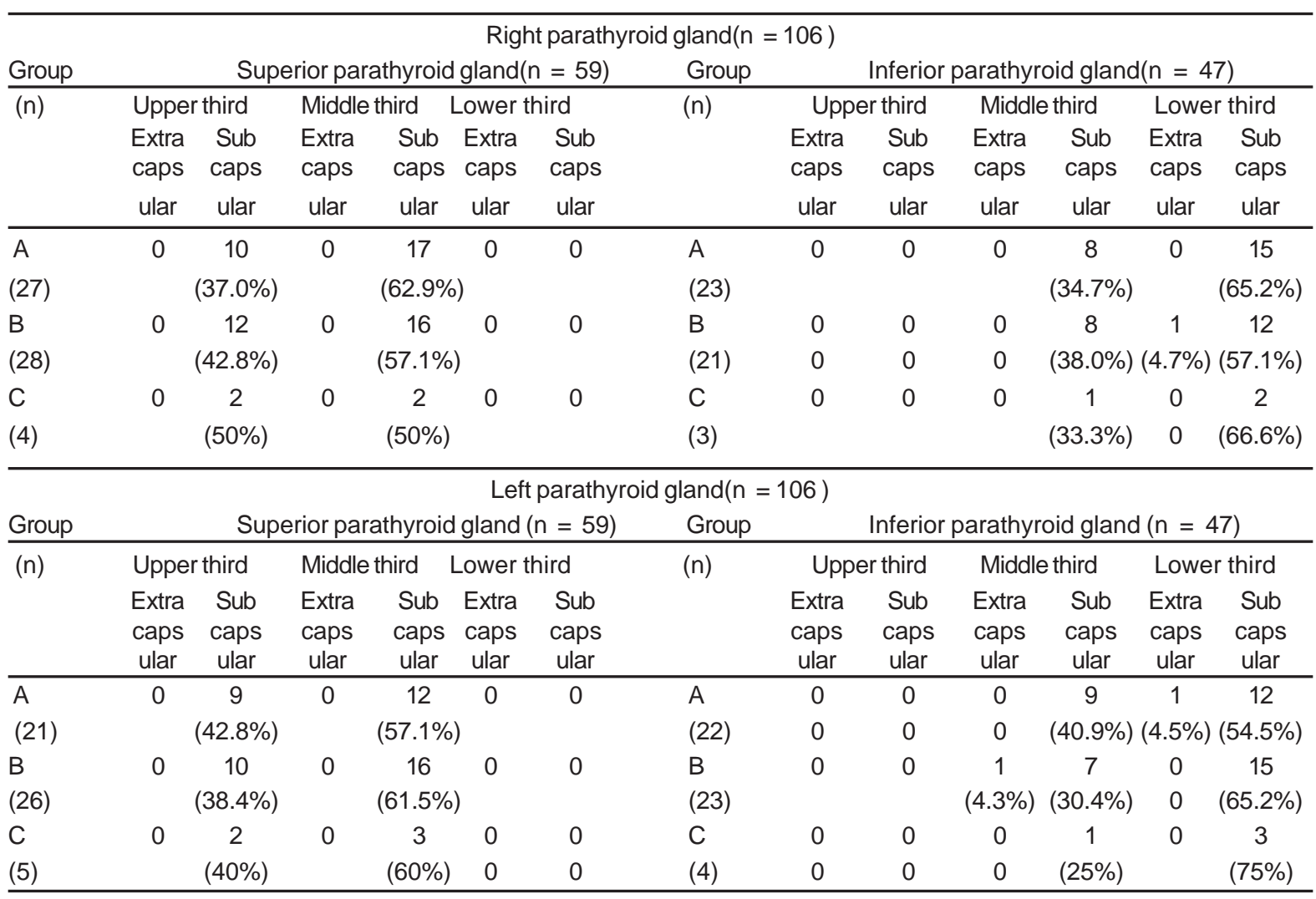

Upper third: $45(21.74 \%)$

Middle third: 101 (48.79\%)

Lower third: $61(29.47)$ 
Table-III

Number of parathyroid glands identified in male and female of different age groups

\begin{tabular}{llcc}
\hline $\begin{array}{l}\text { Group } \\
(n)\end{array}$ & $\begin{array}{l}\text { Sex } \\
(n)\end{array}$ & $\begin{array}{c}\text { No. of } \\
\text { parathyroid } \\
\text { gland identified }\end{array}$ & $\begin{array}{c}\text { Percentage } \\
(\%)\end{array}$ \\
\hline $\mathrm{A}(27)$ & Male(21) & 73 & 35.27 \\
& Female(6) & 20 & 9.66 \\
$\mathrm{~B}(28)$ & Male(21) & 72 & 34.78 \\
& Female(7) & 26 & 12.56 \\
$\mathrm{C}(5)$ & Male(5) & 16 & 7.73 \\
& Female(0) & 0 & 0 \\
\hline
\end{tabular}

Table-IV

Number of paired parathyroid glands in male and female of different age groups

\begin{tabular}{llcc}
\hline $\begin{array}{l}\text { Group } \\
(\mathrm{n})\end{array}$ & $\begin{array}{l}\text { Sex } \\
(\mathrm{n})\end{array}$ & $\begin{array}{c}\text { No. of paired } \\
\text { parathyroid gland } \\
\text { pair (number) }\end{array}$ & $\begin{array}{c}\text { Percentage } \\
(\%)\end{array}$ \\
\hline $\mathrm{A}(17)$ & Male(13) & $13(52)$ & 21.67 \\
& Female(4) & $4(16)$ & 6.67 \\
$\mathrm{~B}(18)$ & Male(13) & $13(52)$ & 21.67 \\
& Female(5) & $5(20)$ & 8.33 \\
$\mathrm{C}(3)$ & Male(3) & $3(12)$ & 5 \\
& Female(0) & 0 & 0 \\
\hline
\end{tabular}
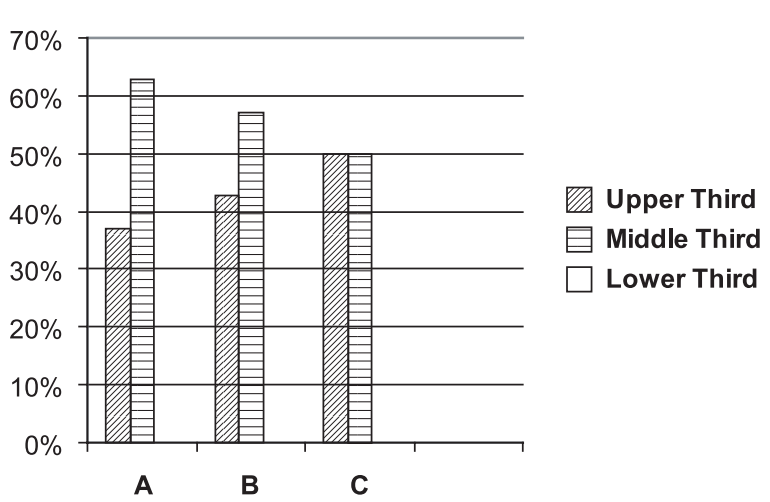

Fig.-1.1: Location of superior parathyroid gland of right side in relation to posterior border of thyroid lobe

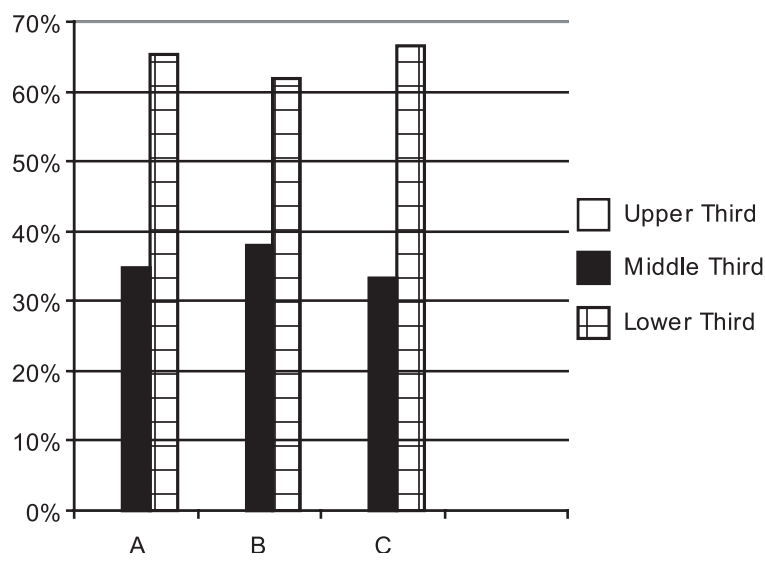

Fig.-1.2: Location of inferior parathyroid gland of right side in relation to posterior border of thyroid lobe

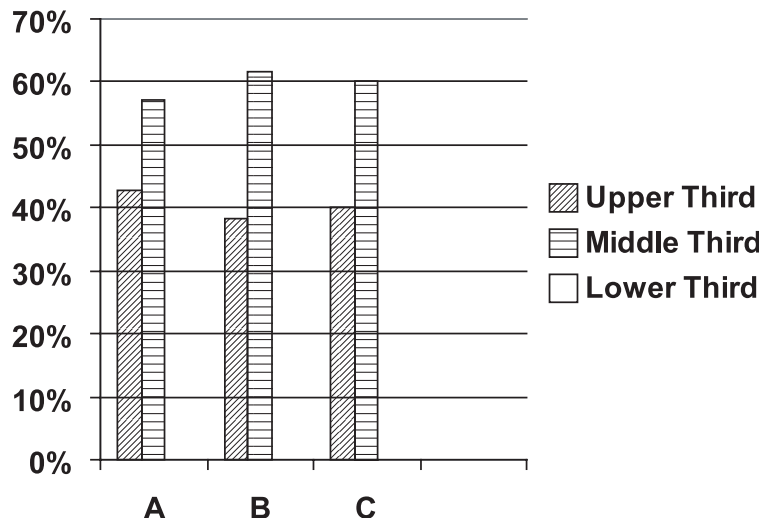

Fig.-1.3: Location of superior parathyroid gland of left side in relation to posterior border of thyroid lobe

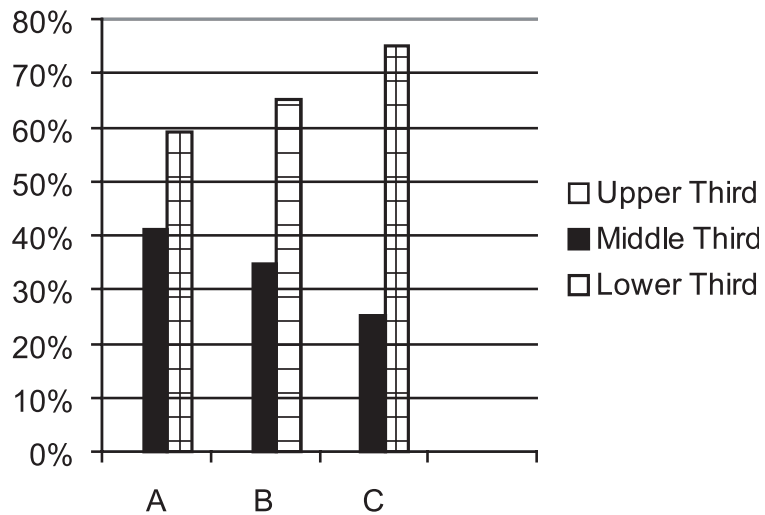

Fig.-1.4: Location of inferior parathyroid gland of left side in relation to posterior border of thyroid lobe 


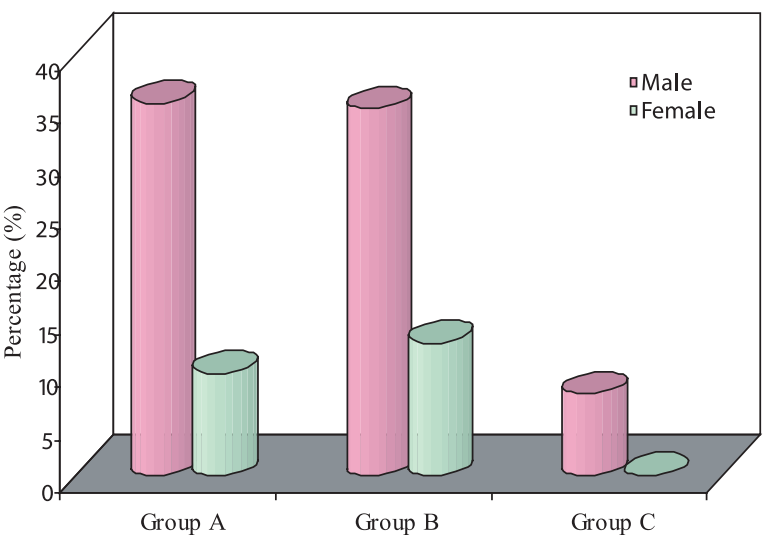

Fig.-2: Number of parathyroid glands identified in male and female of different age groups

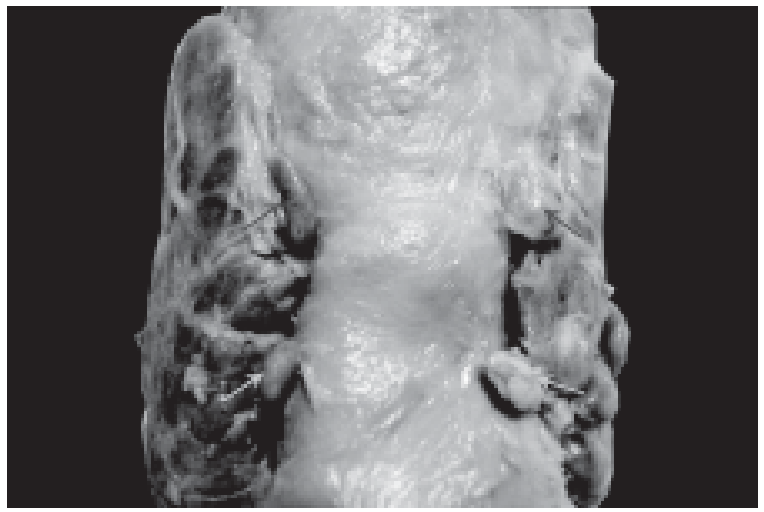

Fig.-4: Showing location of parathyroid glands in relation to posterior border of thyroid lobe (blue arrow indicate superior parathyroid gland and yellow arrow indicate inferior parathyroid gland).

\section{Discussion:}

In the present study of 60 cadavers, 207 parathyroid glands were identified in relation to posterior border of thyroid lobe. And most of the superior parathyroid glands were found on the middle third of the posterior border of the thyroid lobe and most of the inferior parathyroid glands were found on the lower third of the posterior border of the thyroid lobe.

According to Berkovitz ${ }^{2}$ the superior parathyroid glands are more constant in location than the inferior and are usually to be found midway along the posterior borders of the thyroid gland, although they

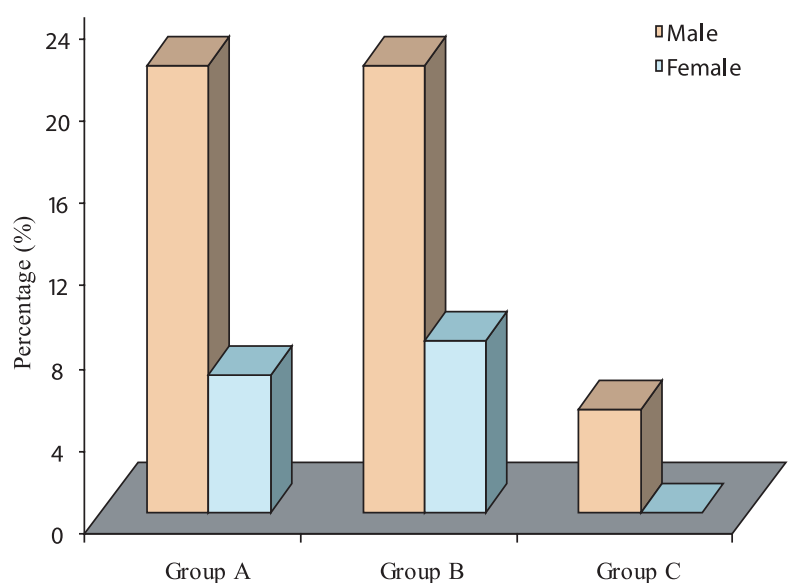

Fig.-3: Number of paired parathyroid glands in male and female of different age groups

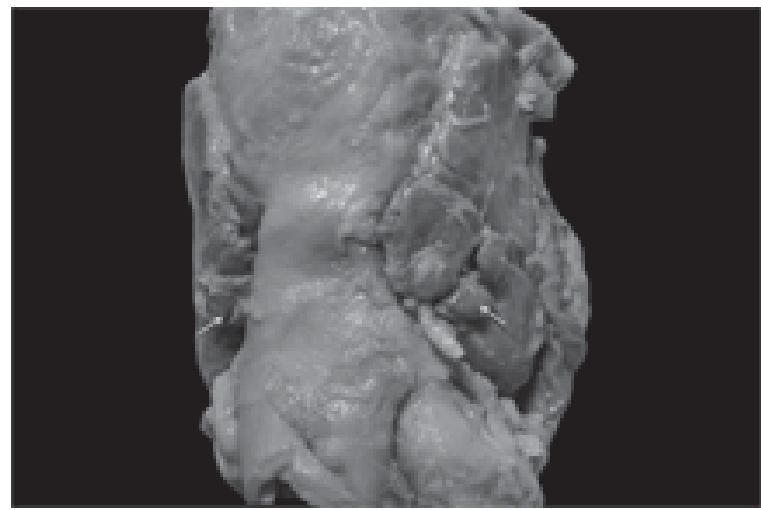

Fig.-5: Showing variation of location of parathyroid glands in relation to posterior border of thyroid lobe (red arrow indicate superior parathyroid gland and yellow arrow indicate inferior parathyroid gland).

may be higher and the inferior pair are usually near the inferior lobar poles. Lahoud and $\mathrm{Abbas}^{7}$ stated that in $99 \%$ of cases, the superior parathyroid are located behind the upper lobes of the thyroid gland and the most common location of the inferior ones (90-95\%) is just near the lower pole of the thyroid. According to Huppert and Reading ${ }^{8}$ the majority of superior parathyroid glands are located dorsal to the middle or upper portion of the thyroid and inferior parathyroid glands are more variable in location and can be found anywhere from the angle of the mandible to the pericardium. Wang ${ }^{9}$ studied 645 parathyroid glands and observed that $77 \%$ of the 
superior parathyroid glands were located at the junction of the upper and middle one third of the thyroid gland and $22 \%$ behind the upper pole of the thyroid. And $42 \%$ of the inferior parathyroid glands were located on the posterior surface of the lower pole of the thyroid gland and rest of the inferior glands were occupied by an ectopic position. According to Sultana et al. ${ }^{10}$ and Enayetullah ${ }^{11}$ most of the parathyroid glands were located opposite the middle third of the posterior border of the thyroid lobe and about one third of all parathyroid glands were related to lower third of the thyroid lobe. Damjanov and Linder ${ }^{12}$ stated that the superior parathyroid glands were situated primarily along the posterior aspect of the middle third of the thyroid and the lower glands were near the lower pole of the thyroid gland. According to Dimashkieh and Krishnamurthy ${ }^{13}$ parathyroid glands can vary in number and location in normal subjects. Most of the superior parathyroid glands are located posterior to the upper poles of the thyroid gland and most of the inferior thyroid glands are located posterior to the lower poles of the thyroid gland.

The finding of the present study has got similarity with the findings of the Berkovitz ${ }^{2}$, Huppert and Reading $^{8}$, Sultana et al $^{10}$, Enayetullah ${ }^{11}$, Damjanov $^{12}$ and the finding of the present study is somewhat dissimilar with the findings of the Lahoud and Abbas $^{7}$, Wang ${ }^{9}$, Dimashkieh and Krishnamurthy ${ }^{13}$ because the position of the parathyroid glands is highly variable (related to their embryological development).

In the present study the highest number of parathyroid glands per person was four, found in about $63.33 \%$ of cases and lowest was one, found in $5 \%$ of cases, two parathyroid glands were found in $8.33 \%$ of cases and three parathyroid glands were found in $23.33 \%$ of cases. The average number of parathyroid glands per person was 3.45.

According to Berkovitz ${ }^{2}$ and MacSween and Whaley ${ }^{14}$ usually there are four parathyroid glands, two on each side (superior and inferior). Damjanov and Linder ${ }^{12}$ stated that four parathyroid glands were present in $90 \%$ to $97 \%$ of individuals with a variation from two to twelve glands. Lifshitz ${ }^{15}$ stated that $84 \%$ of the individuals have four parathyroid glands. Butterworth and Nicholson ${ }^{16}$ studied 241 parathyroid glands and found that $85 \%$ persons had four glands, $8 \%$ persons had supernumerary glands and $7 \%$ had only three glands. According to Quinn Jr. ${ }^{17}$ there are usually four parathyroid glands (two superior and two inferior). However, some persons may have more than four glands, with $6 \%$ of the population believed to have five glands and $0.5 \%$ have six glands. Huppert and Reading ${ }^{8}$ stated that humans are generally considered to have four (paired superior and inferior) parathyroid glands. However, super numerary glands have been described in $2-16 \%$ of the general population, while fewer than four glands are found in $<6 \%$ of the population. Sultana et $\mathrm{al}^{10}$ and Enayetullah ${ }^{11}$ observed that the average number of the parathyroid glands per person was 3.4 and 2.8 respectively.

The finding of the present study corresponds with the findings of the Berkovitz ${ }^{2}$, MacSween and Whaley ${ }^{14}$, Damjanov and Linder ${ }^{12}$, Lifshitz ${ }^{15}$, Butterworth and Nicholson ${ }^{16}$, Quinn Jr. ${ }^{17}$, Huppert and Reading ${ }^{8}$, Sultana et $\mathrm{al}^{10}$.

\section{Ethical clearance:}

This research work was approved by the Ethical Review Committee of Dhaka Medical College, Dhaka.

\section{Acknowledgement}

We express our heartfelt gratitude to the authority of Health, Nutrition and Population sector Programme (HNPSP) of Directorate General of Health Services (DGHS) of Government of the People's Republic of Bangladesh and Dhaka Medial College for providing us the research grant.

\section{References:}

1. Rosai J. Rosai and Ackerman's surgical pathology. Vol. 1. $9^{\text {th }}$ ed. New Delhi: Elsevier Mosby; 2004. p. 595-610.

2. Berkovitz BKB editor. Head and neck. In: Standring S, Ellis $\mathrm{H}$, Healy JC, Johnson D, Williams A, Collins $P$, et al. editors. Gray's anatomy: the anatomical basis of clinical practice. $39^{\text {th }}$ ed. London: Elsevier Churchill Livingstone; 2005. p.564-5, 617.

3. Russell RCG, Williams NS, Bulstrode CJK. Bailey \& Love's Short practice of surgery. $24^{\text {th }}$ ed. London: Arnold; 2005. p. 805-12. 
4. Cameron JL. Current surgical therapy. $8^{\text {th }}$ ed. Philadelphia: Elsevier Mosby; 2004. p. 60214.

5. Panijan RP, Grbesa D, Mederal P, Jezek D, Cavcic A, Gorsic I. Do parathyroid glands from individuals of different age and gender contain lymph vessels?. Coll. Antropol 2006; 30(2): 369-373.

6. Romanes GJ. Cunningham's manual of practical anatomy. Vol. 3.15 th ed. New York: Oxford University Press; 2005. p. 64-8.

7. Lahoud L, Abbas J. The operative approach to parathyroid adenoma. American University of Beirut-Surgery 2002; 1(3): 1-6.

8. Huppert BJ, Reading CC. Parathyroid sonography: Imaging and intervention. J Clin Ultrasound 2007; 35: 144-55.

9. Wang $C$. The anatomic basis of parathyroid surgery. J Ann Surg 1976;183: 271- 5.

10. Sultana SZ, Mannan S, Sultana S, Khan MK, Rahman MH, Hossain A, et al. Morphological study of parathyroid in relation to thyroid gland of Bangladeshi people. Mymensingh Med J 2007 July; 16(2): 137-42.

11. Enayetullah M. Gross and histomorphological study of the thyroid and parathyroid glands in Bangladeshi people (M. Phil. Thesis). Dhaka: University of Dhaka; 1996.

12. Damjanov I, Linder J. Anderson's pathology. $10^{\text {th }}$ ed. Baltimore: Mosby; 1996. p. 1980-2008.

13. Dimashkieh $\mathrm{H}$, Krishnamurthy $\mathrm{S}$. Ultrasound guided fine needle aspiration biopsy of parathyroid gland and lesions. Cyto Journal 2006; 3(6): 1-7.

14. MacSween RNM, Whaley K. Muir's textbook of pathology. $13^{\text {th }}$ ed . London: Arnold;1995. p. 1103-5.

15. Lifshitz F. Pediatric endocrinology. $4^{\text {th }}$ ed. New York: Marcel Dekkfr; 2003. p. 421-70.

16. Butterworth PC, Nicholson ML. Surgical anatomy of the parathyroid glands in secondary hyperparathyrpidism. J R Coll Surg Edinb 1998; 43: 271-3.

17. Quinn FB, Jr. Parathyroid diseases. 1997: Available from: http://www.utmb.edu/otoref/ Glands/parath.htm. 